\title{
TANITMA 1: “Bat Kültüründe Türk Atasözleri” kitabı üzerine
}

\section{Mehmet TUNCER1}

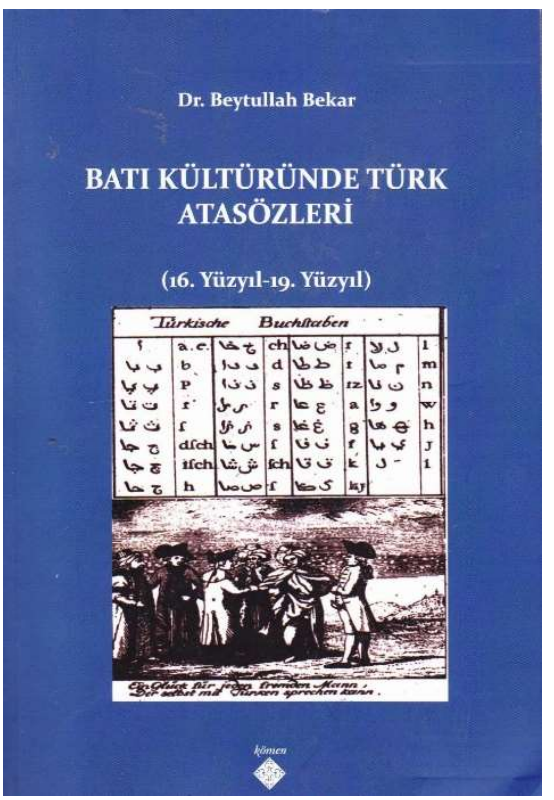

Atasözleri, taşıdıkları birikim ile ait oldukları milletin mazisini aksettiren, anlamları itibariyle de o millete yol gösteren yapılardır. Bu yapıların her biri, onlarca yılda binlerce zihinden süzülerek ait oldukları milletin mazisinin mührünü üzerinde taşıyan bir öz hâline gelmiş ve küçücük yapılarıyla millî hafızanın bir ürünü olarak maziden ana, andan da atiye uzanan bir şuur taşıyıcısı olmuştur (Alemdar, 2018:XIX).

Dilin söz varlığı içerisinde, tecrübelerden yola çıkılarak ortaya konan, zamanla ilk söyleyeni unutulduğu için halka mâl olmuş, o toplumun nevi şahsına münhasır hayat telakkisini, değer yargılarını barındıran yılların birikim ve tecrübelerini öğ̈̈tlere, genel kurallara dönüştüren atasözleri, tarihsel süreçte hafizalarda korunarak şifâhî olarak aktarılagelirken yazının icadıyla birlikte sözlü kültür ortamının yanında yazı ile de kayıt altına alınmaya, derlenmeye ve eserlerde toplanmaya başlanmıştır.

Türk kültürü özelinde bakıldığında Orhun Yazıtları'ndan başlamak üzere Türk dilinin yapı taşları olan Dîvânü Lugati’t-Türk, Kutatgu Bilig gibi eserlerde atasözlerine rastlanmakta ve atasözlerinin tarihi seyrini ${ }^{2}$ bu eserlerde izlemek mümkün olmaktadır (Gönen, 2015:14). Türkçenin elimizdeki en eski yazılı metinlerinden itibaren hemen hemen her eserde az veya çok karşımıza çıkmakta olan atasözlerinin tespiti, hem geçmişi doğru anlamak ve o birikimden faydalanmak hem de bu yapıları gelecek kuşaklara aktarabilmek adına önemlidir (Alemdar, 2018: XX).

Bu bağlamda atasözlerinin önemine ve vazgeçilmezliğine dair yaygın bir kanaat bulunmakla birlikte, bizim ülkemizde doğrudan atasözlerini konu edinen eserlerin ortaya çıkması, Tanzimat döneminde yani 19.yüzyılın ikinci yarısında mümkün olmuştur.Hâlbuki Batı kültüründe Türk atasözleri 16.yüzyıldan itibaren kayıt altına alınmaya ve incelenmeye başlanmıştır. Kimi Lâtin kimi Arap alfabesiyle yazıya geçirilen bu atasözleri, Türk dilinin ifade zenginliği ve anlam dünyasını ortaya koymanın yanında günlük konuşma dilinin doğallığını ve çeşitliliğini de yansıtmaktadır (Özkan'dan akt: Bekâr, 2019: III).

İfade edildiği üzere Osmanlı döneminde yabancı araştırmacılar da atasözleriyle ilgili çalışmalar yapmışlar, atasözlerini derleyerek kendi dillerine aktarmışlar, anlamaya çalışmışlardır. Bu noktada Mohaç Meydan Savaşı (1526) siyasi ve ekonomik açıdan olduğu kadar Türk dili için de önemli sonuçlar doğurmuştur. Batı ile Osmanlı arasında gelişen ilişkiler, Batılıların Osmanlıyı daha yakından tanımak için Lâtin harfleriyle çeşitli eserler kaleme almalarına ve Türkçe öğrenmek için kitaplar yazmalarına neden olmuştur. Transkripsiyon metinleri olarak adlandırılan bu eserlerde sözlükler, bir yabancının

1 Ars. Gör., Kırklareli Üniversitesi, Fen-Edebiyat Fakültesi, Türk Dili ve Edebiyatı Bölümü, Halkbilimi ABD (Kırklareli, Türkiye), mtuncer38@hotmail.com, ORCID ID: 0000-0002-6625-5589 [Makale kayıt tarihi: 17.03.2020-kabul tarihi: 20.03.220; DOI: 10.29000/rumelide.706548]

Atasözlerinin tarihsel süreçte zaman, mekân, bağlam ve inanç sistemleri gibi pek çok unsura göre biçim ve içerik yönünden değişimlere uğradığı bilinmektedir. Dolayısıyla yazı dilinde zamanla tamamen unutulmuş, kullanımı azalmış ve bir yöre ile sınırlanmış atasözlerine de rastlamak mümkün olmaktadır.Detaylı bilgi için bkz: (Gönen, 2015). 
Osmanlı topraklarında seyahat ettiği zaman ihtiyaç duyacağı diyalog metinleri, dua metinleri, atasözleri, Nasreddin Hoca fikraları gibi çok çeşitli Türkçe malzemeler bulunmaktadır (Bekâr, 2019: 1).

Köklü ve zengin bir kültür birikimine sahip Türkler’in atasözleri hakkında literatüre bakıldığında kimisinin sadece derleme kimisinin çeşitli veçhelerle tahlile dayalı olduğu yerli-yabancı, akademikpopüler ciddi bir eser yekûnunun mevcudiyeti göze çarpmaktadır. Bu eserlerden biri olarak tanıtmaya çalışacağımız "Batı Kültüründe Türk Atasözleri (16.Yüzyıl-19.Yüzyıl)", yazarının ifadesiyle uzun ve meşakkatli bir mesainin ürünü olarak ilgilisine zengin bir içerik sunmaktadır.

\section{“Batı Kültüründe Türk Atasözleri (16.Yüzyıl-19.Yüzyıl)”}

Dr.Beytullah BEKÂR tarafından hazırlanan "Batı Kültüründe Türk Atasözleri” başlıklı çalışmada 16.yüzyıldan 19.yüzyılın sonuna kadar Lâtince, İtalyanca, Almanca, Fransızca ve İngilizce olarak hazırlanmış 25 farklı transkripsiyon metninde bulunan 4.289 atasözü bir araya getirilerek incelenmektedir. Kömen Yayınları tarafından 2019 yılı Aralık ayında yayımlanan eser, temelde "Giriş" (s.1-10), transkripsiyon metinleri ve imlâ özellikleri hakkında bilgilerin verildiği I.bölüm (s.11-52), transkripsiyon metinlerinde geçen atasözlerinin eser sıralı ve alfabetik sıralı olmak üzere iki alt başlık halinde ele alındığı II.bölüm (s.53-482) ve atasözleri, deyimler ile kalıp sözler ve özel adlar dizinlerinin yer aldı̆̆ı III.bölüm (483-802) olmak üzere dört ana başlıktan müteşekkildir.

Giriş bölümünde, atasözlerinin ehemmiyeti ve milli kültür içerisindeki yerine değinen yazar, batılı araştırmacıların Osmanlıyı daha yakından tanımak amacıyla yaptıkları çalışmalardan kısaca bahsederek içinde Türk atasözü bulunan ilk transkripsiyon metninin, tespitine göre B. Georgiević’in 1544 tarihli ‘De Turcarum Ritu Et Ceraemoniis' başlıklı eseri olduğunu, bu eserin Türkler hakkında bilgi veren Lâtince bir kitapçık olmasına rağmen içinde bir atasözü tespit edildiğini, daha sonraki tarihlerde Türk atasözleriyle ilgili müstakil kitap hüviyetinde çalışmalara rastlanılmakla birlikte daha çok gramer kitapları içinde atasözlerine yer verildiğini belirterek çalışmasının sınırlarından bahseder. Buna göre katalog taraması neticesinde çalışmasına merkez ittihaz ettiği transkripsiyon metinlerinde geçen atasözlerinin yer aldığı, ilk Türk atasözünün geçtiği eserin tarihlendirildiği (1544) 16.yüzyıldan 20.yüzylla kadarki dönemde bu yüzyllara ait yirmi beş eserin künye bilgilerine yer verir.3 Giriş

Çalışmaya kaynaklık teşkil eden mezkur 25 eser şunlardır: 1) Georgiević, B. (1544). De Turcarum Ritu Et Ceraemoniis. Antverpia 2) Megiser, H. (1605). Paroemiologia Polyglottos. Lipsiae: Sumtibus Henningis Grosii 3) Megiser, H. (1612). Institutionum linguae turcicae. Lipsiae: Magiserus 4 ) Montalbano, G. B. (1632). Turcicae linguae per terminos latinos. İtalya: Napoli Milli Kütüphanesi . 5) Hrabskius, J. - Fincelius, H. W. (1655). Proverbia quaedam Arabica, Persica, \& Turcica: In Gratiam Praedictarum Linguarum Cultorum Edita. Wittenberg: Wilhelm Fincelius. 6) Francesco, M. M. (1670). Syntagmaton Linguarum Orientalium. Stamperia della Sacra Congregazione de Propaganda Fide (Roma). 7) Harsany, J. N. (1672). Colloquia Familiaria Turcico Latina Seu Status Turcicus Loquens. Coloniae Brandeburgicae. 8) Timoteo, A. (1688). Proverbii utili, e virtuosi in lingua araba, persiana, e turca. In Padova: Nella Stamperia del Seminario. 9) Donado, G. B. (1688). Della Letteraturade' Turchi, Osservationifatte da Gio. per Andrea Poletti. all'insegna dell'Italia, a San Marco. 10) Donado, G. B. (1688). Raccolta curiosissima d'Adaggi Turcheschi trasportati dal proprio. Per Andrea Poletti all' Italia. 11) ?. (1689). "Proverbia turcica cum versione italica et latine" \& "Iterum Proverbia turcica, quorum major pars latinis literis scripta est." 12 ) Vaughan, Th. (1709). A Grammar Of The Turkish Language. London: Publisher, J. Humphreys. 13) Clodius, J. Ch. (1729). Grammatica Turcica Necessariis regvlis praecipvas lingvae difficvltates illvstrans (etc). Lipsiae: Wolffgangvm Deer. 14) Preindl, J. von (1789). Grammaire Turque: D'une toute nouvelle methode d'apprendre cette langue en peu de semaines avec un vocabulaire. Berlin: Enrichi D'anecdotes Utiles et Agreables. 15) Pianzola, B. (1789). Dizionario, Grammatiche, e Dialoghi Per Apprendere le Lingue Italiana, Greca-Volgare, e Turca, e Varie Scienze. Podova: Fermo. 16) Dombay, F. von (18.yy). Proverbiorum Turcicorum Centuria I-IV \& Proverbia Turcica Quadraginta. İngiltere: Manchester John Rylands Kütüphanesi. 17) Jaubert, P. A. (1823). Elements de la grammaire turke. Paris: Dundey-Dupre Pere et Fils. 18) Hindoglu, A. (1829). Theoretisch=pracktische Türkische Sprachlehre für Deutsche. Anton Edler v. Schmid. Wien. 19) Wickerhauser, M. (1853). Wegweiser zum Verständnis der türkischen Sprache. Eine deutsch-türkische Chrestomathie. Wien: K.K. Hof-und Staatsdruckerei. 2o) Fleischer, H. F. (1853). Der vollkommene und schnelle türkische Selbstlehrer. Wien: Albert A. Wenedikt Verlag.21) Schlechta Wssehrd, O. F. von (1865). Osmanische Sprichwörter. Wien: K.K. Orientalische Akademie. 22) Piqure, P. J. (1869). Grammatik der türkisch-osmanischen Umgangssprache. Wien: Albert A. Wenedikt Verelag. 23) Wahrmund, A. (1869). Praktisch Handbuch der osmanisch-türkischen Sprache I-III. J. Rickersche 
bölümünde yer alan "Transkripsiyon Metinlerindeki Atasözlerinin Sayısı ve Alfabesi" başlığı altında eserlerin yayın yarihi, yazıldıkları alfabe ve barındırdıkları atasözü sayısı şematik halde derli toplu sunulmuştur. Akabinde içerdiği izahat ve örneklerle neşrin anahtarı hüviyetindeki "Kitabın Hazırlanmasında İzlenen Yöntem” başlı̆̆ı okuyucuya yol gösterici niteliktedir.

Birinci bölüm transkripsiyon metinleri, imlâ özellikleri ve atasözleri incelemesi olmak üzere üç temel başlı̆̆ı ihtiva etmektedir. Bölümün “Transkripsiyon Metinleri” kısmı açıklamalı bir bibliyografya niteliğindedir. Okuyucuya ağyârını mâni efradını câmi halde yayın tarihleri sırasına göre 25 eser (transkripsiyon metni) hakkında bilgiler vermiştir. Kendi içinde sistematiğin gözetildiği alt başlıklarda sırasıyla bulunabildiyse eserin yazarı hakkında bilgiler, eserin muhtevası, dili, temel vasıfları ve özellikle atasözlerinin ne şekilde ele alındığı vurgulanmıştır.4 Bölümün "İmlâa Özellikleri" başlığı altında ise ünlü ve ünsüz harflerin yazımı örneklerle gösterilmiştir. Transkripsiyon metinlerindeki atasözlerinin incelenmesi sonucu tespit edilen hususların sıralandığı "Değişime uğramadan günümüze kadar gelen atasözlerine örnekler", "Taranan eserlerde tespit edilemeyen atasözlerine örnekler", "Atasözünde geçen bir kelimenin Türkçe, Arapça veya Farsça kullanımına örnekler”, "Anlam değişmesine neden olacak şekilde farklı kullanımlara sahip atasözlerine örnekler”, “ Dinî metinlerdeki bazı sözlerin atasözü olarak verilmesine örnekler”, "Arapça ve Farsça sözlerin Türkçe olarak verilmesine örnekler”, "Atasözü olarak verilen deyimlere örnekler”, "Bir (iki) atasözünün iki farklı (bir) atasözü olarak kullanımına örnekler”, "Yanlış veya eksik yazılan atasözlerine örnekler" ile "Hikayeleştirilen atasözlerine örnekler" alt başlıklarına sahip “Atasözleri İncelemesi” kısmı tespitlerin isabeti, örneklerin zenginliği ve özellikle anlam değişmesine neden olacak şekilde farklı kullanımlara sahip atasözü örnekleriyle orijinallik taşımaktadır.

İkinci bölüm çalışmanın en hacimli bölümüdür. Transkripsiyon metinlerinde geçen atasözleri eser sıralı ve alfabetik sıralı olmak üzere iki alt başlık halinde ele alınmıştır. Eser sıralı atasözleri listesi verilirken eserlerin yayın tarihi esasına göre alfabetik sıra gözetilmiştir.

Üçüncü bölümde ise dört ayrı dizin bulunmaktadır. Birinci dizin, atasözleri dizini olup alfabetik sırayla ikinci bölümde toplu halde verilen atasözlerini göstermektedir. İkinci dizin deyimler ve kalıp sözler dizinidir. Burada transkripsiyon metinlerinde atasözü olarak geçen deyimler ile atasözleri içinde bulunan deyimler verilmiştir. Üçüncü dizinde kelime ve kelime grupları bulunmaktadır. Dördüncü dizin ise özel adlar dizinidir. İkinci, üçüncü ve dördüncü dizinler ikinci bölümde yer alan eser sıralı atasözlerinin yerlerini işaret etmektedir. I., II. ve III. dizinler sayfa ve satır numarasına göre değil, eserler için kullanılan kısaltmalara ve kitaptaki alfabetik sıra numarasına göre hazırlanmıştır. Dizinde, atasözlerinin Lâtin harfli orijinal yazılışlarının Türkiye Türkçesi Lâtin harflerine aktarılmış şekilleri esas alınmıştır. Üst madde başı olarak kelimelerin Türkiye Türkçesindeki imlâsı, onun altında da eserlerdeki imlâları verilmiştir.

Buchhandlung. Giessen. 24) Fink, L. (1872). Türkischer Dragoman, Grammatik, Phrasensammlung und Wörterbuch der türkischen Sprache. Leipzig: F.A. Brockhaus Verlag. 25) Müller, A. (1889). Türkische Grammatik, mit Paradigmen, Litteratur, Chrestomathie, und Glossar. Berlin: H. Reuther.

4 Örnek: 1.1.12. Vaughan, Th. (1709). A Grammar Of The Turkish Language. London: Publisher, J. Humphreys. A Grammar Of The Turkish Language adlı eser Thomas Vaughan tarafindan İzmir'de hazırlanmış ve 1709 yılında Londra'da basılmıștır. Yazar hakkında bilinen aslen tüccar olduğu ve İzmir'de belli bir süre yaşadığıdır. Eser, Türkçe öğretimi için İngilizce hazırlanmış ilk kitap olarak bilinir (Güneş 2018: 7). 103 sayfa olup 21 bölümden oluşmaktadır. 1. - 17. bölümlerde Türkçenin ses ve şekil bilgisi hakkında bilgiler vardır. 18. bölümde diyaloglar, 19. bölümde fabl, 20. bölümde 53 atasözü ve son bölümde İngilizce - Türkçe küçük bir sözlük bulunmaktadır. Atasözlerinden önce verilen fabldan yazar çıarılması gereken ders olarak "Az tamah, çok ziyan" atasözünü vermiş olması nedeniyle eserdeki atasözlerinin sayısı 54'tür. Atasözleri 71-76 sayfalar arasında, iki sütun halinde, bir tarafta Türkçe karşısında da İngilizce çevirisi ve Lâtin harfleriyle alfabetik sırayla verilmiştir. 
Çalışma kaynakçanın ardından transkripsiyon metinlerinden örneklerin yer aldığı sayfalarla hitama erdirilmiştir. Nihayetinde Dr.Beytullah Bekâr'ın batılı araştırmacıların eserlerindeki atasözlerini bir araya getirerek incelediği bu çalışmasıyla, Paremiyoloji'den maada farklı disiplinlerin ilgi sahasına girerek araştırma nesnesi olabilen atasözleri üzerine ilgililerinin yapacağı çalışmalara derli toplu veri sunmanın, işlerini kolaylaştırmanın ötesinde Türk kültürüne yaptığı katkı izahtan vârestedir.

\section{Kaynakça}

Aksoy, Ö.A. (1988). Atasözü ve Deyimler Sözlüğü. İstanbul: İnkılâp Yayınevi.

Alemdar, E. (2018). Kaynaktan Eğitime Atasözleri ve Deyimler Çelebioğlu Abdulhakim Hakkı Atalar Sözü Mecmuası (1-538.Sayfalar). (Yayımlanmamış doktora tezi) Marmara Üniversitesi, Eğitim Bilimleri Enstitüsü, Türkçe ve Sosyal Bilimler Eğitimi Anabilim Dalı, İstanbul.

Bekâr, B. (2019). Batı Kültüründe Türk Atasözleri (16.Yüzyll-19.Yüzyıl). Ankara: Kömen.

Gönen, Y.Ö.(2015). Türk Atasözlerinde Sözlü İletişim Unsurlarını Sunumu. (Yayımlanmamış doktora tezi). Ege Üniversitesi, Sosyal Bilimler Enstitüsü, Halkla İlişkiler ve Tanıtım Anabilim Dalı, İzmir. 